\title{
Low Fluctuation of Symptoms May Delay Diagnosis of Myasthenia Gravis: A Case Series
}

\author{
Andreea Dragusin • Nicolae Grecu • Athena Cristina Ribigan (D) • \\ Raluca Stefania Badea · Elena Oana Terecoasa · Amalia Ene • \\ Cristina Tiu
}

Received: November 3, 2021 / Accepted: December 7, 2021 / Published online: December 18, 2021

(C) The Author(s) 2021, corrected publication 2022

\section{ABSTRACT}

Introduction: Myasthenia gravis is an autoimmune disorder affecting neuromuscular transmission, and its hallmark is fluctuating muscular weakness affecting the ocular, bulbar, respiratory, or limb muscles. Our objective is to highlight the difficulties encountered in diagnosing this disorder in patients lacking this characteristic phenomenon.

Methods: Three cases of patients presenting with progressive weakness of bulbar and ocular muscles, in whom a lack of fluctuation delayed the diagnosis of myasthenia gravis, are described.

Results: Amyotrophic lateral sclerosis was considered in two of the patients, while cavernous sinus thrombosis was initially diagnosed in the third. Electrodiagnostic, pharmacologic, and serologic testing ultimately established the diagnosis of myasthenia gravis.

Conclusion: While the typical clinical pattern of myasthenia gravis is well known and easily

A. Dragusin · N. Grecu · A. C. Ribigan $(\bowtie)$.

R. S. Badea - E. O. Terecoasa - A. Ene · C. Tiu

Neurology Department, University Emergency

Hospital of Bucharest, 169 Splaiul Independentei,

050098 Bucharest, Romania

e-mail: athena.ribigan@umfcd.ro

A. C. Ribigan - R. S. Badea - E. O. Terecoasa - C. Tiu

"Carol Davila" University of Medicine and

Pharmacy, 8 Bulevardul Eroii Sanitari, 050474

Bucharest, Romania recognizable, there are cases when the diagnosis, and thus the treatment, is delayed because of low or absent fluctuation of symptoms. The acknowledgment of this probably underestimated presentation is important for expeditious management.

Keywords: Myasthenia gravis; Low-fluctuating; Case series

\section{Key Summary Points}

Symptom fluctuation is a hallmark of myasthenia gravis

Three cases of myasthenia gravis with low or no fluctuation are presented

Absence of fluctuation can further delay diagnosis and treatment

Low-fluctuating myasthenia gravis could be an underestimated phenotype of this disease

Patients with chronic fatigability can benefit from screening for myasthenia gravis 


\section{INTRODUCTION}

Myasthenia gravis (MG) is an autoimmune, antibody-mediated disorder of neuromuscular synaptic transmission resulting in either isolated or combined cranial and predominantly proximal skeletal muscle weakness [1]. About two-thirds of patients experience ocular symptoms at disease onset, while up to $15 \%$ present with involvement of bulbar muscles. Fatigability, the worsening of muscle strength in relation to exercise, and the subsequent fluctuation of symptoms are considered hallmarks of the disease [2].

Diagnosis is established based on clinical presentation and detection of specific autoantibodies [3]. Other tests, such as repetitive or sustained movements, the ice pack test, edrophonium administration, repetitive nerve stimulation, or single-fiber electromyography, can be used to support the diagnosis before antibody testing or in seronegative patients [4].

Until this moment, there are scarce data in the literature concerning myasthenia gravis patients with low or no fluctuating motor symptoms. While rare, this particular pattern usually leads to an important delay of the diagnosis and subsequently of the treatment. The aim of this article is to describe clinical and laboratory findings in patients with myasthenia gravis presenting without the characteristic fluctuation of symptoms.

\section{METHODS}

We present three consecutive patients referred to our Neurology Department for low- or nonfluctuating cranial nerve symptoms in whom a final diagnosis of myasthenia gravis was established. All patients signed a consent stating their non-opposition to the use of medical data, including its publication. The research was performed in accordance with the Declaration of Helsinki and GDPR standards.

All patients underwent clinical examination by neurologists with experience in neuromuscular disorders (strength was tested for individual muscle groups but no standardized MG scale was used as this was not the initial diagnostic suspicion), cerebral imaging, electrodiagnostic examination (EDX), thoracic imaging, and acetylcholine receptor antibody (AChR-Ab) and muscle specific tyrosine kinase antibody (MuSK$\mathrm{Ab})$ testing. AChR-Ab testing was performed using radioimmunologic assay, while MuSK-Ab was performed using enzyme-linked immunosorbent assay. All patients had followup periods up to 1 year after diagnosis.

\section{RESULTS}

Clinical presentation and results of tests are detailed in Table 1 for all patients.

The first patient is a 64-year-old male with no significant medical history, who was admitted for slowly progressive dysphagia; he had been previously examined in an outpatient clinic, and a suspicion of bulbar-onset amyotrophic lateral sclerosis (ALS) was raised. He denied any fluctuation of symptoms. As EDX was not consistent with ALS, a complementary $3-\mathrm{Hz}$ RNS was performed, which was diagnostic for MG. Intramuscular neostigmine was afterwards administered, with significant improvement of the dysphagia and dysphonia. The patient was given oral pyridostigmine and lowdose oral methylprednisolone, which resulted in normal muscle strength and normal deglutition throughout the rest of hospitalization. Subsequent serologic testing revealed the presence of acetylcholine receptor antibodies (AChR-Abs) at a titer of $30.05 \mathrm{nmol} / \mathrm{l}$ (upper limit of normal $<0.25 \mathrm{nmol} / \mathrm{l}$ ).

The second patient is a 79-year-old male presenting for progressive dysphonia and dysphagia. He had been previously examined in otorhinolaryngology and gastroenterology departments, but no specific pathology could be identified. Of note, the patient complained of severe weight loss, but no obvious muscle atrophies could be distinguished. As EDX did not fulfill criteria for ALS, a 3-Hz RNS was performed showing a decrement of $>10 \%$ in only one nerve/muscle group. Serologic testing came back positive for AChR-Abs at a titer of $4.92 \mathrm{nmol} / \mathrm{l}$. Of note, titin and ryanodine antibodies were positive, but imaging of the thorax and abdomen revealed no anomalies. The 
Table 1 Clinical and laboratory findings in MG patients

\begin{tabular}{|c|c|c|c|}
\hline & Patient 1 & Patient 2 & Patient 3 \\
\hline Sex & $\mathrm{M}$ & $\mathrm{M}$ & $\mathrm{F}$ \\
\hline Age (years) & 64 & 79 & 62 \\
\hline Presenting symptom & Dysphagia & Dysphagia, dysphonia & Unilateral eyelid ptosis \\
\hline $\begin{array}{l}\text { Duration of symptoms } \\
\text { before presentation }\end{array}$ & 6 months & 4 months & 3 days \\
\hline \multirow[t]{5}{*}{ Neurologic examination } & Dysphonia & Severe dysphonia & Left eyelid ptosis \\
\hline & $\begin{array}{l}\text { Impaired gag reflex weak } \\
\text { palatal movements }\end{array}$ & $\begin{array}{l}\text { Impaired gag reflex weak palatal } \\
\text { movements }\end{array}$ & Left abducens palsy \\
\hline & Neck flexors weakness $3 / 5$ & Tetraparesis $3 / 5$ MRC & \\
\hline & MRC & Cachexia & \\
\hline & $\begin{array}{l}\text { Upper limb distal weakness } \\
\text { 4/5 MRC }\end{array}$ & & \\
\hline Initial diagnosis & Bulbar-onset ALS & Bulbar-onset ALS & $\begin{array}{l}\text { Cavernous sinus } \\
\text { thrombosis }\end{array}$ \\
\hline $\begin{array}{l}\text { Cerebral contrast-enhanced } \\
\text { CT }\end{array}$ & - & - & $\begin{array}{l}\text { Left cavernous sinus } \\
\text { thrombosis }\end{array}$ \\
\hline Cerebral MRI & $\mathrm{N}$ & $\mathrm{N}$ & $\mathrm{N}$ \\
\hline Spinal cord MRI & - & Multiple cervical disc protrusions & - \\
\hline Intramuscular neostigmine & Improvement & - & Improvement \\
\hline NCS & $\mathrm{N}$ & $\begin{array}{l}\text { Moderately reduced motor and } \\
\text { sensory amplitudes }\end{array}$ & $\mathrm{N}$ \\
\hline Needle EMG & $\begin{array}{l}\text { TA, VL, FDI, deltoid, } \\
\text { genioglossus }-\mathrm{N}\end{array}$ & $\begin{array}{l}\text { Fibrillation potentials in FDI } \\
\text { TA, VL, trapezius, mentalis-N }\end{array}$ & $\begin{array}{l}\text { TA, VL, FDI, deltoid, } \\
\text { mentalis-N }\end{array}$ \\
\hline 3-Hz RNS & $\begin{array}{l}>15 \% \text { decrement in } \mathrm{ADM} \\
\text { and trapezius }\end{array}$ & $>10 \%$ decrement in anconeus & $\mathrm{N}$ \\
\hline Thymus pathology & No & No & Thymoma \\
\hline
\end{tabular}

- not performed, $A D M$ abductor digiti minimi, $A L S$ amyotrophic lateral sclerosis, $E M G$ electromyography, $F$ female, $F D I$ first dorsal interosseus, $M$ male, $M R C$ Medical Research Council, $N$ no anomalies relevant to the presenting symptoms or clinical suspicion, $N C S$ nerve conduction studies, $R N S$ repetitive nerve stimulation, $T A$ tibialis anterior, $V L$ vastus lateralis 
patient received oral pyridostigmine and methylprednisolone, with remission of symptoms.

The third patient is a 62-year-old female presenting for headache and unilateral eyelid ptosis and diplopia. As cerebral imaging suggested cavernous sinus thrombosis, she was given oral anticoagulant, with apparent slight improvement in eye movement; no coagulopathy was identified but a frontal sinus infection was considered as potential trigger for the thrombosis. She presented 1 month later for bilateral eyelid ptosis and worsening of diplopia; clinical examination revealed bilateral asymmetric oculomotor palsy and left abducens palsy. EDX showed no anomalies, including on 3-Hz RNS, but intramuscular neostigmine test was positive. AChR-Abs were present, at a titer of $5.96 \mathrm{nmol} / \mathrm{l}$. She received pyridostigmine and methylprednisolone with gradual improvement of both diplopia and eyelid ptosis. Chest tomography revealed a mediastinal mass for which she subsequently underwent surgery; pathology was suggestive of thymoma.

All patients had subsequent regular followup visits up to 1 year. Corticotherapy was gradually reduced and stopped for patients 1 and 3 , with the first patient requiring reintroduction of the therapy due to proximal upper limb weakness; he furthermore presented with a myasthenic crisis 1 year after diagnosis, requiring the addition of corticoid-sparing immunosuppression afterwards. Patient 2 remained stable on pyridostigmine and low-dose methylprednisolone.

\section{DISCUSSION}

Myasthenia gravis may be misdiagnosed as motor neuron disease, especially when the initial presentation is due to the involvement of bulbar muscles; lack of obvious fluctuation of symptoms can be additionally confounding, as seen in patients 1 and 2. Furthermore, as nutritional intake is reduced secondary to dysphagia, patients lose weight but generally there is no muscle atrophy (which would be expected in ALS), as was the case in patient 2.
Eyelid ptosis and/or diplopia, usually asymmetric, is the initial presentation in about two thirds of patients with MG [2]. As patient 3 presented ipsilateral headache at symptom onset and presented no obvious fluctuation of symptoms, the suspicion of a cavernous sinus pathology was raised. Contrast-enhanced CT showed an apparent filling defect of the ipsilateral cavernous sinus. Given the important bone artifacts that can interfere with visualization of the cavernous sinus, the normal MRI appearance, and subsequent diagnosis of MG, we concluded that a cavernous sinus thrombosis was unlikely in our patient. Additionally, while the CT scan showed a thickening of frontal sinus mucosa, the lack of associated symptoms and serum inflammatory changes made the diagnosis of an acute sinus infection doubtful.

Electrodiagnostic studies are a useful tool for the evaluation of neuromuscular junction disorders. Current guidelines suggest a threshold of $10 \%$ decrement between the first and fourth/fifth CMAPs for 3-Hz RNS in at least one muscle [5]. However, a decremental response is not specific for myasthenia gravis and can be encountered in several neuromuscular disorders, including ALS; furthermore, this is generally more frequent in proximal limb muscles, a pattern also seen in MG [6-9]; 3-Hz RNS has an overall rather low sensitivity, especially in ocular forms of myasthenia gravis [10]. Additionally, the examination of the cranial muscles may be rendered difficult by poor muscle relaxation, stimulator movement, and unstable baseline [9]; this was the case for patient 1, in whom nasalis examination was significantly influenced by stimulator movement related to low patient compliance.

Acetylcholinesterase inhibitor administration is another test which can support the diagnosis of myasthenia gravis. As edrophonium is not readily available in Romania, patients 1 and 3 were given $0.5 \mathrm{mg}$ of neostigmine via intramuscular route, with good response; no objective scale such as the Myasthenia Gravis Composite scale was used for the assessment of improvement, but patient 1 presented significantly improved deglutition and patient 3 a decrease in diplopia and ptosis. 
Pharmacologic testing is reported to be second only to single fiber electromyography in terms of sensitivity; while most reports are related to edrophonium testing, as neostigmine has a longer duration of action, it is possible that it is at least as sensitive as the edrophonium test [10].

All of our patients presented AChR-Abs. These antibodies are present in about $85 \%$ of patients with generalized MG and in a lower percentage of those with ocular symptoms, with more recent reports placing their prevalence at up to $65-71 \%$ [11-13]. While there is no correlation between antibody titer and severity of disease, their presence, and possibly titer, may predict progression to a generalized form, but also association to thymus pathology [12, 14, 15]. Furthermore, antibodies against titin indicate the presence of thymoma, especially in $\mathrm{MG}$ patients $<50$ years of age; together with ryanodine receptor antibodies they seem to correlate with a more severe disease course, although evidence is conflicting [3, 16, 17]. All of our patients underwent CT imaging of the thorax, and patient 2 was the only one in whom antibodies against titin and ryanodine receptor were tested and returned positive; however, in this case no thymus pathology was found on imaging.

Fluctuation is described as worsening of symptoms with exercise or throughout the day and is thought to be related to a reduced safety factor secondary to loss of acetylcholine receptors and subsequent neuromuscular transmission failure $[2,18]$. This is not specific to $M G$, as it can be encountered in other neuromuscular junction disorders, mitochondrial diseases, or myopathies [19]. It is usually an occurrence reported by the patient or easily identified during anamnesis or clinical examination. Animal studies have shown that there is a compensatory quantal release of acetylcholine in models of AChR-Ab MG [20]; whether this is sufficient to mitigate fluctuation in some patients or there are other yet undefined factors which contribute to low fluctuation remains to be determined.

To the authors' knowledge, low or no fluctuation of symptoms has only been described in MuSK-Ab MG patients and only one other 92-year-old patient in whom antibody presence was not mentioned [21, 22].

A delay in the diagnosis of MG is frequently described in the literature. One study by Beekman et al. on 100 consecutive patients showed that, for most, the diagnosis was made within 1 year from onset of symptoms, but this was delayed for up to 5 years in $13 \%$ of patients [23]. A more recent study placed the mean diagnostic delay at a little over 1 year for all MG groups, irrespective of age of onset [24]. This has been attributed to some symptoms, such as fatigue, muscle weakness, dysarthria, or dysphagia, which have been considered non-specific, leading to other diagnoses, such as stroke or motor neuron disease [25]. One common feature in all reports is the mention of fluctuating symptoms which, among others, suggested the diagnosis of MG; there are no case series referring to a subset of patients which had low or no fluctuation of fatigue or weakness, and consequently no comparison can be made regarding our three cases. All of our patients had AChRAbs, were in the late-onset and very-late onset subsets of patients, and had a predominantly bulbar and/or cranial involvement; while these characteristics are shared, the rest of their history and laboratory results and their limited number preclude any generalization. We consider it worthwhile to consider the diagnosis of MG even in patients lacking the characteristic fluctuation of symptoms as this can probably delay the correct diagnosis even further. Implementing a protocol of electrophysiologic studies and serologic testing for MG-specific antibodies in cases of patients with chronic motor fatigability but without fluctuations of their symptoms could help identify these atypical presentations as MG.

\section{CONCLUSION}

While fluctuation of symptoms is considered a hallmark of MG, there are cases in which this phenomenon is either subtle or absent, possibly delaying diagnosis. Given that there is a paucity of literature regarding characteristics of patients with MG presenting without fluctuation of symptoms, we believe this is an avenue worth 
investigating to better characterize this population and expedite diagnosis and treatment.

\section{ACKNOWLEDGEMENTS}

We thank the participants of the study.

Funding. No funding was received for this study. The Rapid Service Fee was funded by the authors.

Authorship. All named authors meet the International Committee of Medical Journal Editors (ICMJE) criteria for authorship for this article, take responsibility for the integrity of the work as a whole, and have given their approval for this version to be published.

Author Contributions. Andreea Dragusin: Concept and design, data collection, drafting the manuscript. Nicolae Grecu: Concept and design, data collection, drafting the manuscript. Athena Cristina Ribigan: Critical review of the manuscript. Raluca Stefania Badea: Drafting the manuscript. Elena Oana Terecoasa: Critical review of the manuscript. Amalia Ene: Concept and design, data collection, critical review of the manuscript. Cristina Tiu: Critical review of the manuscript.

Disclosures. Andreea Dragusin, Nicolae Grecu, Athena Cristina Ribigan, Raluca Stefania Badea, Elena Oana Terecoasa, Amalia Ene, and Cristina Tiu have nothing to disclose.

Compliance with Ethics Guidelines. All patients signed a consent stating their non-opposition to the use of medical data, including its publication. The research was performed in accordance with the Declaration of Helsinki and GDPR standards.

Data Availability. The datasets generated during and/or analyzed during the current study are available from the corresponding author on reasonable request.
Open Access. This article is licensed under a Creative Commons Attribution-NonCommercial 4.0 International License, which permits any non-commercial use, sharing, adaptation, distribution and reproduction in any medium or format, as long as you give appropriate credit to the original author(s) and the source, provide a link to the Creative Commons licence, and indicate if changes were made. The images or other third party material in this article are included in the article's Creative Commons licence, unless indicated otherwise in a credit line to the material. If material is not included in the article's Creative Commons licence and your intended use is not permitted by statutory regulation or exceeds the permitted use, you will need to obtain permission directly from the copyright holder. To view a copy of this licence, visit http://creativecommons.org/licenses/by$\mathrm{nc} / 4.0 /$.

\section{REFERENCES}

1. Gilhus NE. Myasthenia gravis. N Engl J Med. 2016;375:2570-81. https://doi.org/10.1056/ NEJMra1602678.

2. Hehir MK, Silvestri NJ. Generalized myasthenia gravis: classification, clinical presentation, natural history, and epidemiology. Neurol Clin. 2018. https://doi.org/10.1016/j.ncl.2018.01.002.

3. Lazaridis K, Tzartos SJ. Myasthenia gravis: autoantibody specificities and their role in MG management. Front Neurol. 2020. https://doi.org/10.3389/ fneur.2020.596981.

4. Benatar M. A systematic review of diagnostic studies in myasthenia gravis. Neuromuscul Disord. 2006. https://doi.org/10.1016/j.nmd.2006.05.006.

5. AAEM Quality Assurance Committee. American Association of Electrodiagnostic Medicine. Practice parameter for repetitive nerve stimulation and single fiber EMG evaluation of adults with suspected myasthenia gravis or Lambert-Eaton myasthenic syndrome: summary statement. Muscle Nerve. 2001;24:1236-8. https://doi.org/10.1002/MUS. 1139.

6. Nicolau S, Kao JC, Liewluck T. Trouble at the junction: when myopathy and myasthenia overlap. Muscle Nerve. 2019. https://doi.org/10.1002/mus. 26676. 
7. Shang L, Chu H, Lu Z. Can the large-scale decrement in repetitive nerve stimulation be used as an exclusion criterion for amyotrophic lateral sclerosis? Front Neurol. 2020. https://doi.org/10.3389/ fneur.2020.00101.

8. Costa J, Evangelista T, Conceição I, De CM. Repetitive nerve stimulation in myasthenia gravis - relative sensitivity of different muscles. Clin Neurophysiol. 2004. https://doi.org/10.1016/j. clinph.2004.05.024.

9. Lamb CJ, Rubin DI. Sensitivity and specificity of repetitive nerve stimulation with lower cutoffs for abnormal decrement in myasthenia gravis. Muscle Nerve. 2020. https://doi.org/10.1002/mus.26999.

10. Meriggioli MN, Sanders DB. Myasthenia gravis: diagnosis. Semin Neurol. 2004. https://doi.org/10. 1055/s-2004-829594.

11. Monte G, Spagni G, Damato V, Iorio R, Marino M, Evoli A. Acetylcholine receptor antibody positivity rate in ocular myasthenia gravis: a matter of age? J Neurol. 2021. https://doi.org/10.1007/s00415020-10342-3.

12. Peeler CE, De Lott LB, Nagia L, Lemos J, Eggenberger ER, Cornblath WT. Clinical utility of acetylcholine receptor antibody testing in ocular myasthenia gravis. JAMA Neurol. 2015. https://doi. org/10.1001/jamaneurol.2015.1444.

13. Pasnoor M, Dimachkie MM, Farmakidis C, Barohn RJ. Diagnosis of myasthenia gravis. Neurol Clin. 2018. https://doi.org/10.1016/j.ncl.2018.01.010.

14. Galassi G, Mazzoli M, Ariatti A, Kaleci S, Valzania F, Nichelli PF. Antibody profile may predict outcome in ocular myasthenia gravis. Acta Neurol Belg. 2018. https://doi.org/10.1007/s13760-018-0943-7.

15. Huang GZ, Lo YL. Correlation between acetylcholine receptor antibody levels and thymic pathology in myasthenia gravis: a review. J Clin Neuromuscul Dis. 2013. https://doi.org/10.1097/ CND.0b013e31828a0090.

16. Szczudlik P, Szyluk B, Lipowska M, Ryniewicz B, Kubiszewska J, Dutkiewicz M, et al. Antititin antibody in early- and late-onset myasthenia gravis.
Acta Neurol Scand. 2014. https://doi.org/10.1111/ ane. 12271.

17. Skeie GO, Aarli JA, Gilhus NE. Titin and ryanodine receptor antibodies in myasthenia gravis. Acta Neurol Scand Suppl. 2006;183:19-23. https://doi. org/10.1111/j.1600-0404.2006.00608.x.

18. Serra A, Ruff RL, Leigh RJ. Neuromuscular transmission failure in myasthenia gravis: decrement of safety factor and susceptibility of extraocular muscles. Ann N Y Acad Sci. 2012. https://doi.org/10. 1111/j.1749-6632.2012.06841.x.

19. Keesey JC. Clinical evaluation and management of myasthenia gravis. Muscle Nerve. 2004. https://doi. org/10.1002/mus.20030.

20. Wang X, Rich MM. Homeostatic synaptic plasticity at the neuromuscular junction in myasthenia gravis. Ann N Y Acad Sci. 2018;1412:170. https:// doi.org/10.1111/NYAS.13472.

21. Delaney Y, Khooshabeh R, Benjamin L. Acute severe ocular myasthenia in a 92-year-old woman. Eye. 2002;16:323-4. https://doi.org/10.1038/sj.eye. 6700098 .

22. Rodolico C, Bonanno C, Toscano A, Vita G. MuSKassociated myasthenia gravis: clinical features and management. Front Neurol. 2020. https://doi.org/ 10.3389/FNEUR.2020.00660.

23. Beekman R, Kuks JBM, Oosterhuis HJGH. Myasthenia gravis: diagnosis and follow-up of 100 consecutive patients. J Neurol. 1997. https://doi.org/10. $1007 /$ s004150050059.

24. Cortés-Vicente E, Álvarez-Velasco R, Segovia S, Paradas C, Casasnovas C, Guerrero-Sola A, et al. Clinical and therapeutic features of myasthenia gravis in adults based on age at onset. Neurology. 2020 . https://doi.org/10.1212/WNL. 0000000000008903.

25. Vincent A, Clover L, Buckley C, Grimley Evans J, Rothwell PM. Evidence of underdiagnosis of myasthenia gravis in older people. J Neurol Neurosurg Psychiatry. 2003. https://doi.org/10.1136/jnnp.74. 8.1105 . 